\title{
Comment on: "Controversies regarding mask usage in ophthalmic units in the United Kingdom during the COVID-19 pandemic"
}

\author{
Ali Poostchi $\mathbb{D}^{1} \cdot$ Mong-Loon Kuet $^{1} \cdot$ Patrick S. Richardson ${ }^{1}{ }^{1} \cdot$ Moneesh K. Patel $^{1}$
}

Received: 7 May 2020 / Revised: 19 May 2020 / Accepted: 21 May 2020 / Published online: 3 June 2020

(c) The Royal College of Ophthalmologists 2020

\section{To the Editor:}

We read with interest the article by Naveed et al. [1] on controversies regarding mask usage in ophthalmic units during the COVID-19 pandemic. We agree that offering patients a surgical face mask will lower the risk of them transmitting infection. We found that placing a mask in front of a breathing simulator led to a tenfold reduction in particle transmission [2].

We would, however, question their assertions that UK guidance for Personal Protective Equipment (PPE) falls short and that FFP3 respirators should be mandated for dealing with symptomatic individuals. The WHO, CDC and ECDC recommend that respirators should be prioritised for use in high risk aerosol generating procedures and that surgical face masks are acceptable in other situations when treating individuals with suspected or confirmed COVID-19 [3].

In addition, there is robust evidence from a large randomised control trial showing that in outpatients, there is no benefit from using N95 (FFP2) respirators compared with surgical face masks to reduce influenza and other respiratory viral illnesses in health care workers [4]. Subsequent meta-analyses have shown similar results with the benefits of respirators likely offset by discomfort with prolonged use leading to more frequent manipulation or reduced compliance [5].

There is an added danger that using these respirators will lead to a false sense of security when in reality, PPE is only one part of an integrated approach to infection control.
Attention should also be given to measures such as streamlined patient flow and scrupulous disinfection which are further up in the 'hierarchy of control'.

\section{Compliance with ethical standards}

Conflict of interest The authors declare that they have no conflict of interest.

Publisher's note Springer Nature remains neutral with regard to jurisdictional claims in published maps and institutional affiliations.

\section{References}

1. Naveed H, Scantling-Birch Y, Lee H, Nanavaty MA. Controversies regarding mask usage in ophthalmic units in the United Kingdom during the COVID-19 pandemic. Eye. 2020. https://doi.org/10. 1038/s41433-020-0892-2.

2. Poostchi A, Kuet ML, Pegg K, Wilde C, Richardson PS, Patel MK. Efficacy of slit lamp breath shields. Eye. 2020. https://doi.org/10. 1038/s41433-020-0940-y.

3. Bahl P, Doolan C, de Silva C, Chughtai AA, Bourouiba L, MacIntyre CR. Airborne or droplet precautions for health workers treating COVID-19? J Infectious Dis. 2020. https://doi.org/10. 1093/infdis/jiaa189.

4. Radonovich LJ Jr., Simberkoff MS, Bessesen MT, Brown AC, Cummings DAT, Gaydos CA, et al. N95 respirators vs medical masks for preventing influenza among health care personnel: a randomized clinical trial. JAMA. 2019;322:824-33.

5. Long Y, Hu T, Liu L, Chen R, Guo Q, Yang L, et al. Effectiveness of N95 respirators versus surgical masks against influenza: a systematic review and meta-analysis. J Evid Based Med. 2020. https:// doi.org/10.1111/jebm.12381.
Ali Poostchi

a.poostchi@nhs.net

1 Department of Ophthalmology, Royal Derby Hospital, University Hospitals of Derby and Burton NHS Foundation Trust, Derby, UK 